\title{
Oedema of Feet and Ankles in Rheumatoid Arthritis
}

\author{
K. SWINBURNE,* M.A., M.B., B.CHIR.
}

Brit. med. F., 1964, 1, 1541-1544

Patients with rheumatoid arthritis often have oedema of the feet and ankles. This is mentioned by Hollander (1960) in the following terms: "At the ankle, oedema from causes other than joint disease is common. Painless pitting oedema of the lower legs and about the ankle is often from old phlebitis or varicosities if unilateral, or from nutritional, cardiac, or renal deficiency if bilateral. Swelling from arthritis of the ankle joint is tender, and, in low-grade chronic swelling, is usually limited to the reflections of the synovium of the ankle, particularly below the malleoli." It was felt that this description does not correspond with our experience of the phenomenon of oedema of the feet and ankles in rheumatoid arthritis, and the studies described here were carried out in an attempt to clarify the immediate cause of this oedema.

\section{Material and Methods}

Forty patients with rheumatoid arthritis (American classification) and oedema were investigated. Each review includes a full history, clinical examination, collection of blood, and, when possible, oedema fluid by the method of acupuncture. The 40 patients comprised 32 women and $8 \mathrm{men}$. Of these, 28 were seropositive and 12 were seronegative for the rheumatoid factor. Eighteen specimens of oedema fluid were obtained-16 from women and 2 from men. Ten were from seropositive and eight from seronegative cases.

Oedema fluid was examined microscopically to exclude the presence of red cells and inflammatory cells. Some of the phenomena of rheumatoid arthritis (pain, oedema, capillary dilatation) may be explained on the basis of histamine release. and oedema fluid was therefore assayed for histamine biologically. A portion of guinea-pig ileum was suspended in a 5-ml. organ bath, with oxygen bubbling through Tyrode solution. The sensitivity of each preparation was determined initially by adding a standard solution of histamine and recording the response on a smoked drum. The preparation was then washed free of histamine with fresh Tyrode solution, after which the test specimen of oedema fluid was added to the tissue bath.

\section{Results}

Laboratory Investigations.-(1) Proteins of serum and oedema fluid have been reported separately (Park and Swinburne, 1964). (2) Oedema fluid was very pale yellow, or colourless, in all cases. There was no clotformation in any of the specimens of oedema fluid. No cells were found on microscopical examination, which rules out contamination with blood and the presence of inflammatory cells. No evidence of histamine activity was found.

Clinical Studies.-(1) Inflammation: we have found no relation between the presence of oedema and acute inflammation involving the joints of the ankles or feet. (2) Varicose veins have been excluded in both the unilateral and bilateral cases of oedema. (3) Thrombophlebitis has been established in only

* Department of Clinical Medicine, the General Infirmary at Leeds. Now in the Department of Diagnostic Radiology, the General Infirmary at Leeds.
3 of the 40 cases. It is interesting that in each of these cases there was an important associated condition; amyloid disease, systemic lupus erythematosus, and Reiter's syndrome. (4) Other causes: nutritional, cardiac, and renal causes of oedema have been excluded on clinical grounds.

\section{Natural History of the Oedema}

This form of oedema may develop suddenly, over a period of hours, or it may be of such gradual onset that the patient has difficulty in describing when it first occurred. It may appear to be associated with an exacerbation of rheumatoid arthritis or it may develop in a patient whose progress has, in other respects, remained satisfactory. A careful history often shows that the condition has been present intermittently for several years. In this series the duration ranged from one week to ten years.

Oedema may be present for days or weeks, varying only in severity, or it may come and go at short intervals followed by remissions lasting for several months. The swollen feet and ankles are described by the patients as feeling stiff, tense, tender, painful, or heavy. The oedema may be unilateral but is more often bilateral ; it is not necessarily symmetrical, and, in fact, one side is often much more swollen than the other. Swelling can be massaged from one region to another. Wearing elastic stockings does not cure the condition but only transfers the swelling higher up the legs. One patient who complained of swollen knees, and who had been considered to have bilateral joint effusions, was cured of these by giving up her elastic stockings, when the fluid gravitated once more into the feet and ankles.

Oedema usually develops progressively during the day and is most severe at night-time. It develops less quickly if the patient is active and more quickly if he or she is inactive. Thus walking may prevent or relieve oedema whereas standing or sitting may bring it on. This is in contrast to the oedema of congestive heart failure, which is made worse by activity and relieved by rest. The oedema is relieved by resting with the legs elevated and usually disperses overnight. It is relieved by diuretics. It is usually worse in hot weather and better in cool weather. It may also be made worse by local heat, including wax baths or hot bottles. Since this series includes 32 women and 8 men, oedema would, in fact, appear to affect the sexes equally having regard to the sex ratio of rheumatoid arthritis.

In the later stages swelling may be non-pitting as well as pitting, and the two forms may coexist. The non-pitting type of oedema, or chronic hard oedema, becomes particularly prominent around the malleoli, extending both above and below, and may also involve the feet.

From the foregoing description it would appear that this oedema is of vascular origin.

\section{Skin of Feet and Ankles}

The skin of the feet and ankles shows a spectrum of change according to the duration of the rheumatoid arthritis. Early 
cases show a thickened pallid, boggy skin and subcutaneous tissues in which pitting is easily elicited. Later the skin develops a congested appearance, with or without the presence of cyanosis (Fig. 1).

In the course of time cutaneous vessels become more than normally prominent owing to loss of the normal skin texture and loss of subcutaneous fat. A notable feature is the presence

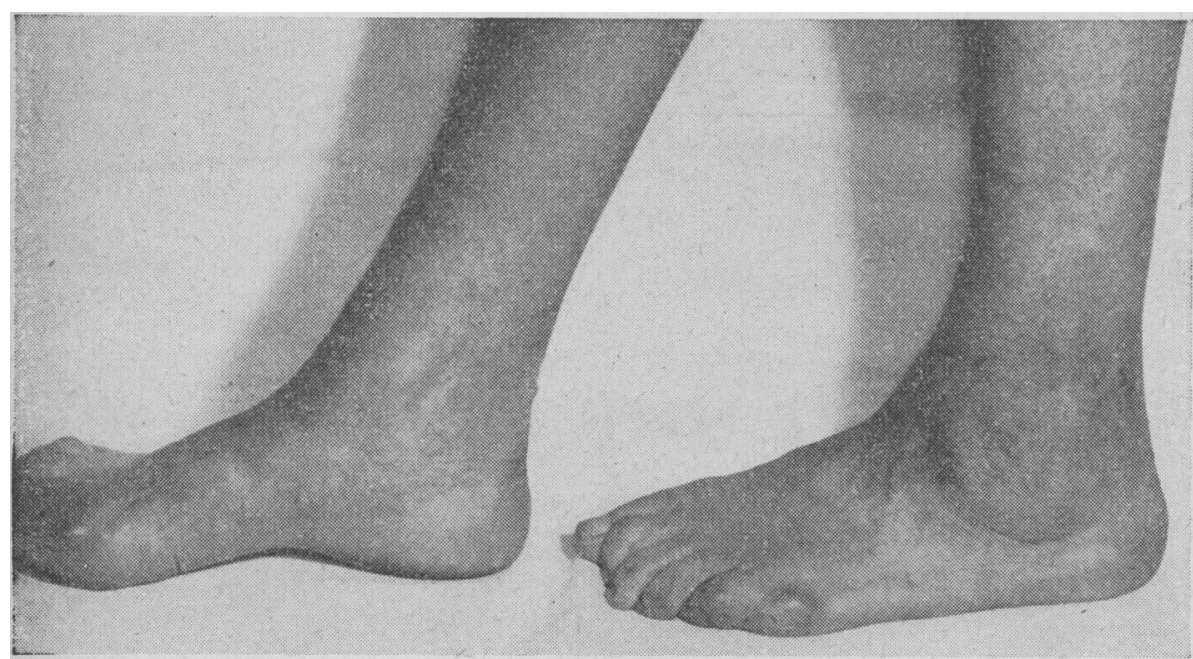

FIG. 1.-Congested appearance of skin of feet and ankles in rheumatoid arthritis.

\section{Effects of Therapy}

A.C.T.H.-In no case was oedema initially attributable to the use of A.C.T.H., but in two cases which required A.C.T.H. therapy oedema became worse for a few days.

Corticosteroids.-Twenty-one patients were receiving prednisolone, 2.5 to $7.5 \mathrm{mg}$. daily, and among the 18 patients from whom oedema fluid was collected nine were on prednisolone and nine were not.

Phenylbutazone.-Four patients were treated with phenylbutazone, $300 \mathrm{mg}$. daily on five days out of seven, and two received a regime of prednisolone with phenylbutazone.

Gold.-None of the patients were receiving chrysotherapy.

Chloroquines.-No patient in this series was receiving treatment with a chloroquine derivative.

Salicylates.-Thirteen patients received " solprin," 15 to 40 gr. daily, and oedema fluid was collected from six of these.

In the 18 cases from whom oedema fluid was obtained, nine were on prednisolone, three were receiving phenylbutazone, and six were treated with salicylates. There was no relation between the presence or absence of oedema and of numerous small vessels, which occur either singly or in leashes (Fig. 2). This makes acupuncture for uncontaminated fluid difficult and often impossible. It was always necessary to search very carefully in order to find a relatively avascular area. The skin was then punctured with a trocar and the needle introduced so that the tip just penetrated the skin. Attempts to introduce the tubes full-length, in the usual way, always provoked bleeding.

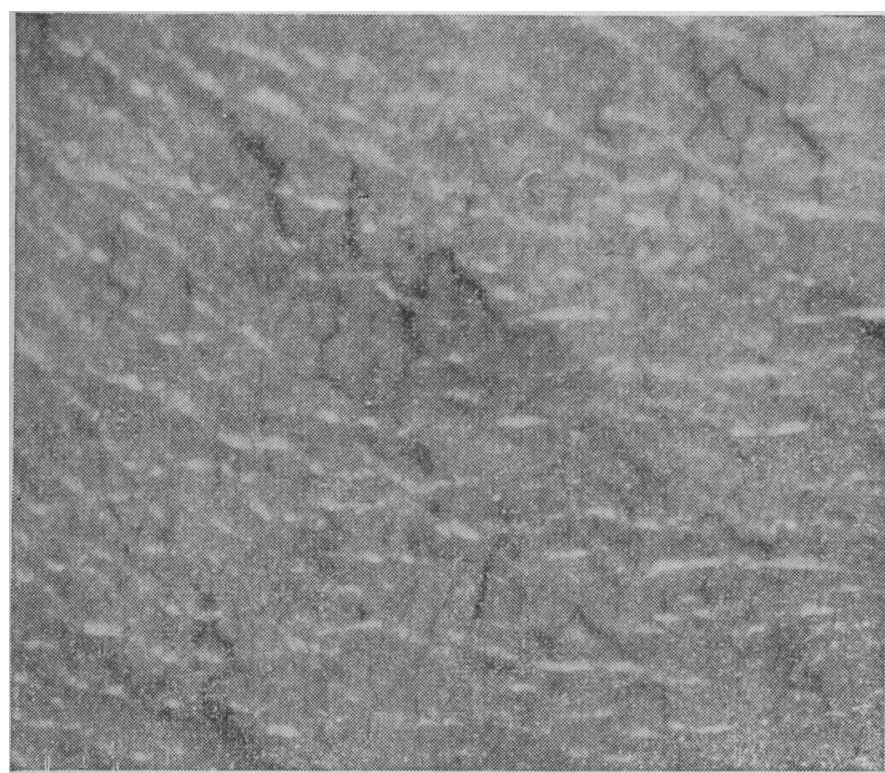
Fig. 2.-Showing numerous small vessels present in skin of feet and
ankles.

In unilateral oedema, comparison of the two sides may reveal important differences in the superficial vessels, well shown by infra-red photography. Fig. 3 shows a normal ankle, with a few dilated vessels in the skin. In Fig. 4, which shows the opposite ankle, oedema is present sufficiently to obscure the lateral malleolus and far more vessels are evident.

These observations on the skin of the feet and ankles in rheumatoid arthritis strongly suggest that the oedema is associated with vascular abnormality. treatment with prednisolone, phenylbutazone, or salicylates. The natural history of the condition was the same in all cases, irrespective of therapy.

In no case was oedema attributable to the use of splints.

\section{Discussion}

Most authorities would probably agree with the view that there is usually more than one underlying cause of oedema (Samuels, 1956 ; Lancet, 1960). On the other hand, Burn (1962) believes that oedema is always due solely to sodium retention, while Hendry (1962) states that the primary cause lies in the (endothelial) membrane and remains to be discovered.

$A$ priori, oedema might be due to a disturbance of one or more of the following factors: capillary permeability, serum colloid osmotic pressure, salt-and-water balance, lymphatic drainage, venous drainage, endothelial membrane activity. The diagnostic value of Crockett's (1956) classification has already been noted. Whereas the division of oedemas into three main groups is acceptable in the light of present knowledge, it seems less certain that it is possible to subdivide group 1 into three distinct subgroups (Table I), for on closer inspection the degree of overlap of the three groups would seem to make this subdivision unjustifiable. Table II shows the actual range of values for each of these subgroups.

TABLE I.-Three Subgroups of the Low-protein Oedemas, Described by Group $1\left\{\begin{array}{l}0.1-0.3 \mathrm{~g} \text {. prock } 100 \mathrm{ml}=\text { = hypoproteinaemia } \\ 0.3-0.5, ", 100,=\text { heart failure } \\ 0.6-0.9, ", 100,=\text { venous incompetence }\end{array}\right.$

TABLE II.-Total Range of Oedema-fluid-protein Values in the Three Subgroups of Crockett, Showing That There is Considerable Overlap Between the Three Species

$$
\text { Group } 1\left\{\begin{array}{l}
0 \cdot 1-0.6 \mathrm{~g} \text {. per } 100 \mathrm{ml}=\text { =hypoproteinaemia } \\
0.2-1.6, \%, 100,=\text { heart failure } \\
0.4-1.0, \% 100,=\text { venous incompetence }
\end{array}\right.
$$

Altered Capillary Permeability.-It has been shown that there is no increase of capillary permeability in these subjects, which rules out an inflammatory or allergic cause for the oedema.

Lymphatic Insufficiency.-Lymphoedemas have high protein values-1-5 g. $/ 100 \mathrm{ml}$.- and the level of protein rises progres- 
sively the longer the oedema has been present (Drinker et al., 1934 ; Crockett, 1956 ; Exton-Smith and Crockett, 1957 ; Taylor et al., 1958). The oedema associated with rheumatoid arthritis is a low-protein oedema, with no relation between protein level and duration (Fig. 5), and is therefore not a lymphoedema.

Lowered Colloid Osmotic Pressure of Serum.-Reduction of the serum proteins and reversal of the albumin-globulin ratio leads to lowering of the colloid osmotic pressure. It is difficult to evaluate the effects of this factor, for colloid osmotic pressure must undergo a marked reduction before any clear-cut relation develops between this and oedema formation. On the other hand, Bennhold (1957) has described a case in which there was absence of serum albumin, but without clinical symptoms, and, in particular, no oedema. The present series shows no relation between the level of serum proteins and the proteins of the corresponding oedema fluid (Fig. 6), which excludes a purely osmotic cause for the oedema. Osmotic effects cannot, however, be excluded completely and may contribute to oedema formation in rheumatoid arthritis.

Salt-and-Water Retention.-The use of A.C.T.H., prednisolone, phenylbutazone, or salicylates does not appear to be the prime cause of this oedema, but it is not possible to say that these drugs do not contribute to oedema formation.

Altered Membrane Activity.-Hendry (1962) has advanced the theory that, ultimately, increased membrane activity is responsible for all abnormal collections of fluid, including oedema. This theory would seem to depend upon the concept that the osmotic effects of relatively small amounts of protein can be ignored. Whether this is in fact the case must await further clarification. However, it is unnecessary to invoke a complex mechanism to explain a phenomenon which can be explained by a simpler one, the alternative offered by Hendry himself -that is, failure of normal reabsorption of fluid-and it is suggested that this is the immediate cause of the oedema.

Altered Venous Function. - Venous oedemas have low protein values with no relation to duration. The series studied by Stead and Warren (1944) had oedema fluid protein values ranging from 0.4 to 1.3 g. $/ 100 \mathrm{ml}$. (mean 0.8 g.). In Crockett's
(1956) group of venous oedemas the protein values were from 0.4 to $1 \mathrm{~g}$. $/ 100 \mathrm{ml}$. (mean $0.73 \mathrm{~g}$.). In Fig. 7 the present series is compared with these two, and it can be seen that the three sets of results correspond reasonably well. The rather greater range of the rheumatoid series might well be explained, on Crockett's thesis, on the basis of multiple pathology and also the effects of treatment.

\section{Conclusions}

The natural history of this oedema, and clinical studies on the skin of the feet and ankles, suggest that the condition is of vascular origin. The oedema-fluid-protein levels compare well with those of the venous oedemas investigated by Stead and Warren (1944) and by Crockett (1956).

In particular, the explanation of this phenomenon given by Hollander (1960) is incorrect. This oedema is, in fact, proper to rheumatoid arthritis and is associated with definite changes in the vasculature of the skin and subcutaneous tissues. It is

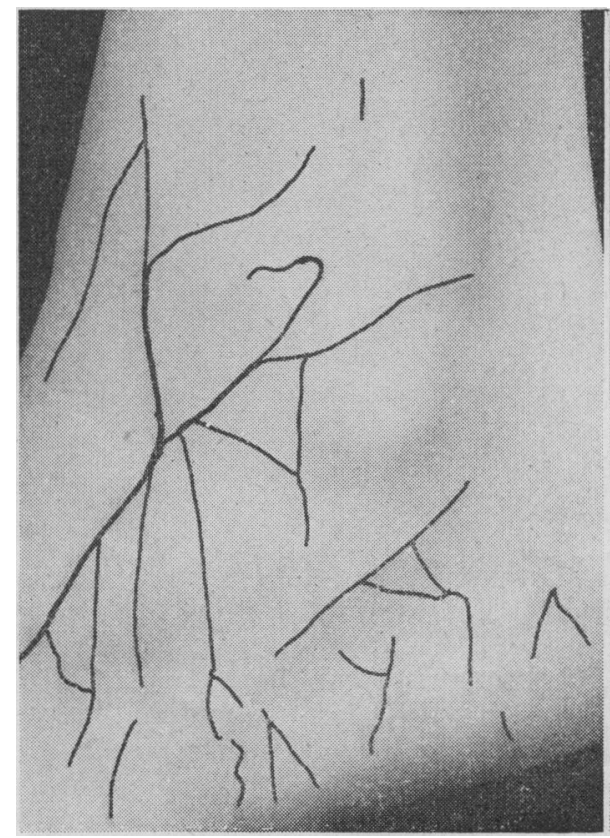

FIG. 3

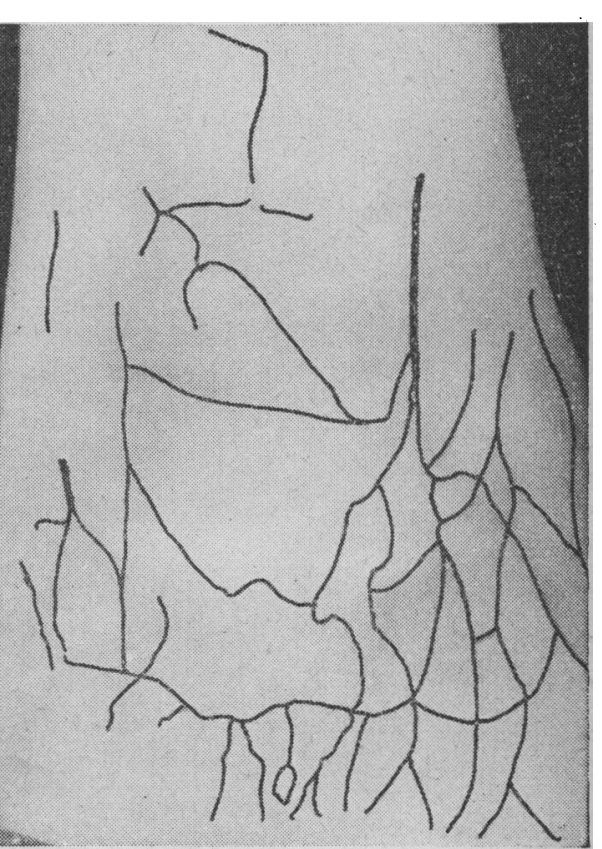

FIG. 4

Indian ink tracings of cutaneous vessels. FIG. 3.-Left ankle of a patient ; no oedema present FIG. 4.-Right ankle of patient in Fig. 3 ; oedema present. This side shows an increase in the number of cutaneous vessels as compared with the normal left side.

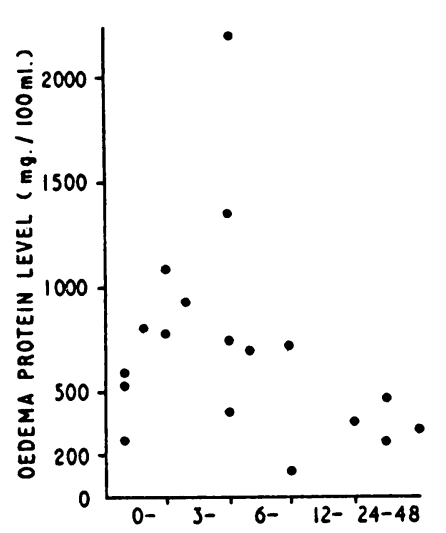

DURATION OF OEDEMA (months)

FIG. 5

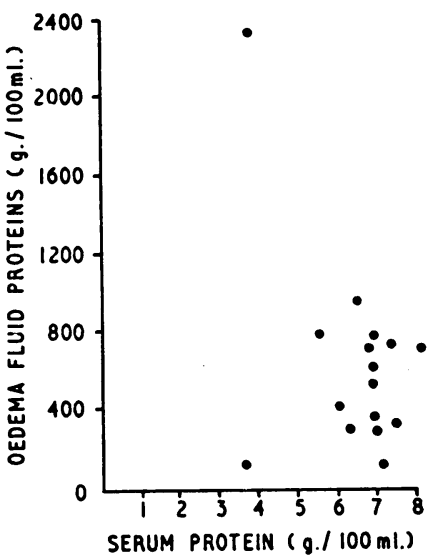

FIG. 6

FIG. 5.-Showing that in the present series there is no relation between oedema protein levels and duration of oedema. FIG. 6.- There is no relation between the oedema fluid pro:ein and serum protein levels.

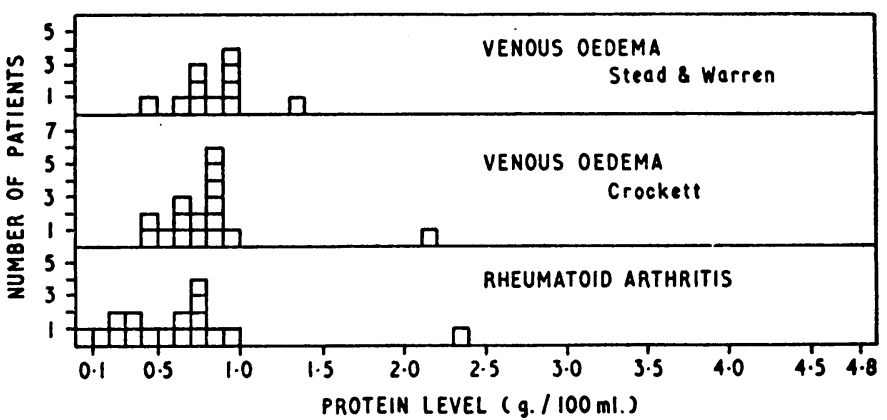

FIG. 7

FIG. 7.-Range of protein values in patients with rheumatoid arthritis compared with range of protein values obtained from patients with venous oedema by Stead and Warren (1944) and Crockett (1956). 
not due to nutritional, cardiac, or renal disease. It is neither inflammatory nor necessarily associated with inflammation of the joints of the feet and ankles. It is not a lymphoedema. It is not painless, but is uncomfortable, tender, or painful. It is not always pitting, becoming solid in the later stages. There is considerable evidence to suggest that this is a venous oedema.

\section{Summary}

Forty patients with rheumatoid arthritis and oedema have been investigated to find the cause of the oedema. Specimens of oedema fluid from 18 of these have been analysed. The oedema is a low-protein oedema, and the protein level bears no relation to duration and no relation to the protein level of serum. There is no relation to inflammation of the joints of the feet and ankles, and no relation to nutritional, cardiac, or renal disease. Varicose veins and thrombophlebitis are not the cause of the oedema. The natural history of this phenomenon suggests that it is a venous oedema, and this is supported by the appearance of the skin of the feet and ankles, and by the oedema-fluidprotein levels.
The explanation given by Hollander is incorrect. Oedema of the feet and ankles should be regarded as a clinical feature of rheumatoid arthritis due to altered venous function.

I should like to thank Professors S. J. Hartfall, A. Hemingway, G. H. Lathe, and D. R. Wood for their advice, interest, and support.

\section{REFERENCES}

Bennhold, H. (1957). Uber Zwei Fälle von Analbuminaemiae. Protides of the Biological Fluids, edited by H. Peeters, p. 223. Elsevier, London.

Burn, J. H. (1962). Drugs, Medicine, and Man, p. 47. Allen and Unwin, ondon.

Crockett, D. J. (1956). Lancet, 2, 1179

Drinker, C. K., Field, M. E., Heim, J. W., and Leigh, O. C., jun. (1934). Amer. F. Physiol., 109, 572 .

Exton-Smith, A. N., and Crockett, D. J. (1957). Brit. med. F., 2, 1280.

Hendry, E. B. (1962). Clin. Chem., 8, 246.

Hollander, J. L. (1960). Arthritis and Allied Conditions, 6th ed., p. 40. Kimpton, London.

Lancet, 1960, 2, 1179.

Park, D. C., and Swinburne, K. (1964). Brit. med. F., 1, 86.

Samuels, S. S. (1956). Diagnosis and Treatment of Vascular Disorders, Chap. 22, p. 556. Williams and Wilkins, Baltimore.

Stead, E. A., jun., and Warren, J. V. (1944). f. clin. Invest., 23, 283.

Taylor, G. W., Kinmonth, J. B., and Dangerfield, W. G. (1958). Brit. med. F., 1, 1159 .

\title{
Smallpox Vaccination in Pregnancy: A Prospective Study
}

\author{
GEOFFREY J. BOURKE,* M.A., M.B., D.P.H., D.C.H. ; RICHARD J. WHITTY,* L.R.C.P.I., D.C.H.
}

Ever since the observation by Gregg (1941) of a high incidence of congenital defects of the eye in children born to women who had had rubella in pregnancy, interest has been stimulated in infections as probable aetiological factors in congenital abnormality or pregnancy wastage. It follows that a similar interest should be taken in the artificial introduction into the body of virus or bacterial products during immunization procedures in pregnancy.

A smallpox outbreak occurred in England and Wales between December 1961 and April 1962. As a consequence of press, radio, and television publicity, the staffs of public health clinics and other doctors in Dublin City received many requests for vaccination against smallpox, and large numbers of people were vaccinated as a result. Despite notices displayed at public health clinics stating that routine smallpox vaccination was contraindicated in pregnancy, it was inevitable that some pregnant women would be vaccinated, and this paper reports a study of the effects on the foetus of smallpox vaccination.

\section{Method}

The population of Dublin City is served by four maternity hospitals, which together account for over $80 \%$ of the births of the city. During the period 2 April to 3 September 1962 of the city. During the peran attending the antenatal clinics of these four hospitals was asked whether or not she had been vaccinated against smallpox during her current pregnancy. If the answer was in the affirmative she was asked for the date and place of vaccination, and was interviewed to determine whether vaccination had been successful or not. Because it was necessary to rely on the patient's statement to assist in interpretation of

- From the Department of Social Medicine, Trinity College, Dublin. successful reactions it was decided to use a history of vesicle ("water blister") which later formed a pustule (" pus blister") and the presence of a recent scar as the criteria of successful vaccination. If the woman had not been vaccinated she was advised against the procedure. The appropriate facts were recorded on each chart.

It should be noted that the woman was not asked direct questions about the reaction but was invited to describe the lesion which appeared on the arm after vaccination. It is realized that omission of the immediate-type reactions will leave in the study only those with the more severe types of vaccination reaction. Consequently the cases we are dealing with are those in which the insult, if any, to the foetus following smallpox vaccination is greatest.

Twelve months later the chart of each vaccinated subject was obtained; the four adjacent charts, two on each side of the index chart, of women who were recorded as being unvaccinated during their pregnancy, and whose first visit to the antenatal clinic was on the same day as the vaccinated subject, were taken as controls. There were, then, four unvaccinated controls for each vaccinated case. It must be mentioned, of course, that, though the unvaccinated had been advised against vaccination, it is not definitely known whether or not they remained unvaccinated throughout the pregnancy. However, where a congenital abnormality, stillbirth, neonatal death, or abortion was recorded among the controls, a home visit was made to inquire whether smallpox vaccination had in fact been done, but none of these controls was found to have been vaccinated during the remainder of the pregnancy. The following facts were recorded from each chart: age, parity, blood group, duration of pregnancy in weeks, the outcome of the pregnancy (whether abortion, stillbirth, neonatal death, congenital abnormality, or normal live birth), the weight and sex of the 